\title{
Organizational working time regimes: Drivers, consequences and attempts to change patterns of excessive working hours
}

\section{Blagoy Blagoev}

Leuphana Universität Lüneburg, Germany

\author{
Sara Louise Muhr \\ Copenhagen Business School, Denmark
}

\section{Renate Ortlieb \\ University of Graz, Austria}

\section{Georg Schreyögg}

Freie Universität Berlin, Germany

\begin{abstract}
A 40-hour working week is the norm in Europe, yet some organizations require 60 or more working hours and in investment banks an alarming 120-hour weeks are known to be worked. What is more, these organizations often require workers to be permanently on call and demonstrate high production rates. Consequences of such practices include frazzled employees, with their families' and their own health under pressure. This article introduces our special issue of the German Journal of Human Resource Management. It tackles the many reasons behind excessive work hours and failed attempts to change working time arrangements in organizations. It first identifies three core ideas in previous research, namely the dispersed nature of regimes of excessive working hours, their high levels of persistence and their constitution at multiple levels of analysis. It then summarizes the contributions in this special issue. Finally, it proposes avenues for future research, such as focusing on the genesis and the historicity of organizational working time regimes, studying the interrelation of factors across multiple levels of analysis, and probing
\end{abstract}

\section{Corresponding author:}

Renate Ortlieb, Department of Human Resource Management, University of Graz, Elisabethstr. 50, Graz, 8010 , Austria.

Email: renate.ortlieb@uni-graz.at 
new theories to explain the extreme persistence of excessive working hours. The overarching aim of our special issue in this core area of human resource management is to contribute to an understanding of organizational working time regimes and the tenacity of excessive working hours in an effort to deepen our knowledge of how to change them.

\section{Keywords}

Change, excessive working hours, overwork, persistence, working time, working time flexibility

\section{Introduction}

Many contemporary workplaces are characterized by persistent working time patterns with more than 60 working hours per week, constant availability and an ever increasing pace of work (Crary, 2013; Mazmanian et al., 2013; Michel, 2011; Perlow, 2012; Snyder, 2016; Wajcman, 2014). Taken together, these factors amount to an 'extreme' work environment (Hewlett and Luce, 2006), widely criticized for its detrimental effects on individuals, families and organizations (Goh et al., 2016; Perlow and Kelly, 2014; Williams et al., 2016).

Firms have begun to react to such criticisms by launching various work-life programmes, such as part-time work, teleworking or flexible and/or reduced hours. Yet the results are disappointing and most programmes fail (Kossek et al., 2011; Moen, 2015; Putnam et al., 2014). Even more sophisticated projects to redesign work often backfire (Perlow and Kelly, 2014). Excessive working hours practices prove incredibly rigid. This special issue of the German Journal of Human Resource Management examines the nature of regimes of excessive working hours, their drivers and consequences as well as attempts to change them. The overarching aim is to understand such regimes and why they still persist today, in order to deepen our knowledge of how to change them. This special issue builds on a conference on Organizational Working Time Regimes held on 30-31 March 2017 at the University of Graz, Austria.

Addressing regimes of excessive working hours constitutes a core issue in human resource management. The reasons for this are multifaceted. Even though the extent to which excessive working hours damage individual health has been subject to debate (Pfeffer, 2018; Pfeffer and Carney, 2018; Ten Brummelhuis et al., 2017; Ten Brummelhuis and Rothbard, 2018; Toker, 2018), they have been associated with various other detrimental organizational outcomes. They impair productivity and creativity (Michel, 2011; Perlow and Porter, 2009), they foster gender inequality (Acker, 1990; Gascoigne et al., 2015; Reid, 2015), and they systematically put employees with household and family obligations at a disadvantage. In short, it is not just individuals and organizations that suffer. More importantly, regimes of excessive working hours are an obstacle to reaching major social goals such as human sustainability and gender equality in the workplace.

At the same time, the high level of persistence of existing working time regimes poses an additional - and even more serious - managerial challenge. Even modest changes in working time arrangements tend to rebound on managers (Perlow, 1997, 1999). Legislation for working time reduction is systematically disregarded (Kellogg, 2011, 2012). Many high-status knowledge workers continue to work between 60 and 80 hours 
per week despite extensive work-life programmes initiated by their employers (Kärreman and Alvesson, 2009; Michel, 2014a; Muhr et al., 2012). In investment banking, both employees and managers reported feeling 'trapped' in a regime of working up to 120 hours per week for years (Michel, 2011). Such 'systematic difficulties [with changing regimes of overwork] generally indicate that something more is going on than simple conservatism' (Meiksins and Whalley, 2004: 76; emphasis added). Novel human resource management approaches to change can only be developed based on a solid understanding of the underlying drivers of this persistence.

The contributors to this special issue not only focus on persistence, they shed light on different dynamics and outcomes of organizational regimes of excessive working hours. In so doing, they advance our knowledge of 'what works' (and what does not) when it comes to changing these regimes. To introduce their work, we begin by summarizing three core ideas about organizational working time regimes: their dispersed nature, their high levels of persistence, and their constitution at multiple levels of analysis. We then highlight how the articles in this special issue advance our knowledge about organizational working time regimes. Finally, we point out implications and opportunities for future research.

\section{Key ideas in previous research on regimes of excessive working hours}

Several previous studies provide an insight into the various individual, relational, organizational, occupational and societal factors that contribute to the proliferation of regimes of excessive working hours (Gascoigne et al., 2015; Golden, 2009). For instance, scholars have debated the extent to which new information and communication technologies that enable 24/7 connectivity, such as smartphones or email, have contributed to the acceleration and intensification of work across occupations (Barley et al., 2011; Mazmanian, 2013; Mazmanian et al., 2013; Perlow, 2012; Wajcman, 2014; Wajcman and Rose, 2011). Another approach seeks to understand how new forms of organizational control in knowledge-intensive organizations (Alvesson, 2000, 2004) can perpetuate excessive working hours and mislead individuals into experiencing their extreme workload as 'self-chosen' by concealing the underlying power dynamics (Costas and Grey, 2014; Costas et al., 2016; Ekman, 2013; Kärreman and Alvesson, 2004, 2009; Lupu and Empson, 2015; Michel, 2011, 2014a; Perlow, 1998). Yet another stream of literature has focused on examining taken-for-granted social and cultural norms such as the gendered 'ideal worker image' (Davies and Frink, 2014; Dumas and Sanchez-Burks, 2015; Reid, 2015) and the related 'work devotion schema', which tend to equate overwork with loyalty, performance and commitment (Blair-Loy, 2003; Williams et al., 2016). Since such norms have become part of career systems (Grey, 1994) in many occupational fields and in increasingly insecure environments (Lupu and Empson, 2015; Ng and Feldman, 2008; Ortlieb and Weiss, 2018), they exert particularly strong power over individuals.

In the following, we distil three conceptual ideas that cut across existing research and, to us, appear central to the study of organizational working time regimes. 


\section{Organizational working time regimes are dispersed}

The first and perhaps most important finding of previous studies relates to the dispersed nature of organizational regimes of excessive working hours. That is, rather than having a single cause, they emerge within a complex web of 'taken-for-granted and mutually reinforcing practices, interactions, expectations, policies, and reward systems that reflect and reinforce the ideal-worker schema' (Kelly et al., 2014: 486). For example, Perlow's (1999) influential work on 'the time famine' demonstrated how (a) interdependent work patterns with their (b) temporal context (i.e. the temporal rhythms of work) and (c) social context (i.e. the systems of rewards, values and norms governing work) are entangled in a self-perpetuating loop. As a consequence of this 'vicious work time cycle' (Perlow, 1999), actors were continuously interrupting each other, thereby slowing down work, expanding working hours and generating a constant feeling of not having enough time.

More recently, and drawing on an ethnography of two investment banks, Michel (2011, 2014a, 2015) has demonstrated that even seemingly unrelated and noncomplementary elements can end up reinforcing one another. In Michel's (2014a) study, practices such as free meals on the job, car services and childcare intended to improve the work-life balance paradoxically end up making bankers work even longer hours. The ensuing 'web of power' (Michel, 2014a: 515) entraps actors in a regime of overwork by shaping their personal dispositions. Because actors are unable to notice how this web shapes them, 'they cannot counteract it and can rarely self-report on it' (Michel, 2014a: 515). In short, it is precisely their dispersed character which makes time regimes difficult to pinpoint and to resist.

Borrowing from research on gender and inequality regimes, we can therefore describe working time regimes as dynamic sociotemporal phenomena that emerge within a web of heterogenous and 'loosely interrelated practices, processes, actions, and meanings' (Acker, 2006: 443). As such, working time regimes constitute second-order patterns, or patterns of patterns. Consequently, they are likely to develop their own distinct dynamics, which might become decoupled from the dynamics of first-order time use (similar to the disconnect in the dynamics of single routines and clusters of multiple interdependent routines, for example; Kremser and Schreyögg, 2016). It is the complex dynamics within this web that can end up reproducing a 'dominant temporal ordering' (Ancona and Chong, 1996: 253) in organizations.

Acknowledging the dispersed character of working time regimes is important for both theoretical and practical reasons. In terms of theory-building, the concept of working time regimes as dispersed patterns of working time patterns provides a novel conceptual frame for integrating the rather fragmented findings of previous research. Such integration is imperative. If scholars keep isolating elements and studying them separately, there is a risk of generating theoretical descriptions that lack the complexity necessary to match the complexity of the empirical phenomenon at hand. This, however, is essential for developing novel approaches to cope with regimes of excessive working hours in practice. Indeed, a major shortcoming of current approaches stems from the fact that they tend to focus on single aspects of the time regime that are perceived as problematic (e.g. workload, flexibility, etc.) and try to tackle them in isolation. To overcome this shortcoming, we need to develop a far better understanding of how diverse yet 
interdependent elements come to work together in the constitution and maintenance of regimes of excessive working hours.

\section{Organizational working time regimes are highly persistent}

A second and related finding that cuts across existing research on regimes of excessive working hours pertains to their often extreme levels of persistence. The persistence of such regimes has emerged as a secondary finding of studies primarily addressing phenomena such as work-family conflict (Bailyn, 2006; Blair-Loy, 2003; Kossek et al., 2011), organizational control and socialization (Covaleski et al., 1998; Kärreman and Alvesson, 2009; Michel, 2011) or organizational responses to macro-institutional change (Kellogg, 2011). Indeed, there is a proverbial 'implementation gap' when organizations adopt new work-life policies (Hobson and Sadar, 2014; Kossek et al., 2011). For instance, Kellogg $(2011,2012)$ found that many hospitals in the United States experience severe difficulties or even completely fail to adapt to new legal requirements for shorter working hours for surgical residents. In investment banking, 'practices that were explicitly intended to achieve work - life balance ended up achieving the opposite, intensifying the pace of work even more' (Michel, 2015: 51). Excessive work hours in management consulting firms persist despite burgeoning work - life discourses and initiatives (Kärreman and Alvesson, 2009; Reid, 2015).

How can we account for this surprising observation that, even when firms explicitly set out to change regimes of excessive working hours, the hours do not change? There are many reasons why most initiatives do not work. One of the major explanations is that they are troubled by a 'flexibility stigma' (Cech and Blair-Loy, 2014; Williams et al., 2013) and are thus rarely utilized by employees who fear marginalization and negative career consequences. Hence, work practices, identities and beliefs that reward time spent at work as a sign of loyalty and commitment and 'fuel extreme working hours' (Williams et al., 2016: 526) remain largely unchallenged by traditional flexibility programmes (Perlow and Kelly, 2014). In recent studies researchers have moved to studying deeper levels of work practices and culture (Reid, 2015). This research, for instance, has shown that group dynamics can generate self-perpetuating vicious cycles of escalating availability and responsiveness to clients and superiors (Mazmanian et al., 2013; Perlow, 2012) that, in turn, perpetuate excessive working hours regimes.

Often it is assumed that new recruits quickly internalize the 'ideal worker image' prevalent in their firms and come to 'hyper-identify' with it, even up to the point of becoming 'corporate clones' (Covaleski et al., 1998: 324). For instance, in her research on overworked investment bankers, Michel (2011) found that most people experienced their extreme workload as 'self-chosen' (p. 336) and resisted questioning the professional norms and identities that required working long hours. Similarly, Kellogg (2011, 2012) found that the majority of senior surgeons formed a 'defender coalition' that employed various status-based counter-tactics in order to block the adoption of a new working hours scheme advanced by their hospital's management. The defenders found that the new regulations fundamentally contradicted internalized norms of devotion to work, leading to identity-based resistance to change. Such observations have led many scholars to conclude that '[o]rganizational change to reshape workplace time norms for 
professionals has been stalled [...] [because] any proposal to redefine work is profoundly threatening to people whose identities have been forged around the old way of doing it' (Williams et al., 2016: 532).

However, the problem with such reasoning is that it essentially shifts the explanation of persistence to a different level, such as occupational norms, the ideal worker image, the work devotion schema, and so on. If changing regimes of excessive working hours fails because of influences from other levels/elements within an organization, basically, the same question then arises on a different level. Why is it that these elements persist? Why are occupational norms, for instance, so persistent? In other words, beyond the fact that regimes of excessive working hours are extremely persistent, only very limited theoretical knowledge is available as to why and how these regimes are maintained amidst purposive efforts to change. In short, we know a lot about the symptoms, but little about the underlying cause that prevents organizations from changing established regimes.

\section{Organizational working time regimes are constituted at the intersection of multiple levels of analysis}

A final central feature of regimes of excessive working hours that emerges from previous studies relates to their constitution at the intersection of multiple levels of analysis. Whereas their dispersed character highlights the need to consider interdependencies among elements on the same level, this aspect, in turn, foregrounds complex interactions across levels. Several examples help to illustrate this point.

First, on the individual level, personal dispositions such as work engagement, workaholism or a compulsive work mentality not only are associated with excessive working hours, but also mediate the extent to which working long hours is associated with negative health outcomes (Ten Brummelhuis et al., 2017). However, as forcefully demonstrated by research on socialization, personal dispositions are not simply individual but instead emerge out of the interaction between persons and the social systems in which they participate (Michel, 2014b). Consequently, taking 'an individualistic perspective on what is inherently a relational dynamic' (Mazmanian, 2013: 1247) risks producing an incomplete and inadequate description of regimes of excessive working hours.

Second, on the group level, vicious cycles like the one discovered by Perlow (1997, 1999) highlight how self-perpetuating relational dynamics of working time regimes are entangled with broader organizational and occupational forces. In Perlow's (1999) case, organizational reward systems that celebrated 'individual heroics' led actors to develop a 'crisis mentality' that meant they focused on solving other actors' current crises instead of completing their own work on time. As a result, actors entrapped themselves in a constant 'firefighting mode' that fuelled long working hours. Importantly, when the author tried to explicitly address the inefficient temporal rhythms of the team, her initiative bounced back at the organizational level despite initial success within the group. Surprised by this puzzling persistence, the author concluded that 'changes $[\ldots]$ are not sustainable if the vicious cycle itself is not altered' (Perlow, 1999: 75). This insight reinforces the importance of considering interactions across multiple levels of analysis when addressing regimes of excessive working hours. 
Finally, organizational-level dynamics, such as the mechanisms of unobtrusive organizational control mentioned earlier (Alvesson, 2000; Costas and Grey, 2014; Kärreman and Alvesson, 2009; Michel, 2011), might be entangled with broader occupational and/or societal dynamics. For example, scholars have argued that normative mechanisms of control (Kunda, 1992) are particularly prevalent in occupations whose work is opaque and therefore difficult to evaluate (Alvesson, 2000; Bailyn, 2006; Brivot et al., 2014; Covaleski et al., 1998). In the absence of objective measures of work quality and/or performance, the number of hours people put into work becomes a useful and accepted proxy (Anderson-Gough et al., 2001; Pentland, 1993). Some have even argued that in certain knowledge-based occupations, working long hours and being constantly available might have become part of the product sold to clients (Mazmanian and Erickson, 2014). In order to develop a more adequate understanding of organizational working time regimes, researchers need to consider how such complex multi-level dynamics shape not only their proliferation but also their maintenance.

\section{Expanding the perspective: The contributions in this special issue}

This special issue covers various time themes highlighted in this introductory article. Although focusing on different aspects, all contributions emphasize the importance of time and time regimes for management research and employees' well-being.

Judy Wajcman opens the contributions with an essay on the relationship between digital technology and working time, and more generally societal acceleration. Her major point is that we should refrain from seeing digital technology as a quasi-external driver. She makes clear that the design of technology has been created by engineers and their idea of how work and life (should) unfold. The author concludes that protesting against long working hours is relevant but falls short of changing the underlying forces. Rather, the making of engineering has to be fundamentally reconsidered.

The contribution by Julia Seitz and Thomas Rigotti highlights the effects of working time autonomy in terms of flextime. Drawing on data from the Socio-economic Panel, (SOEP) they examined a sample of 4019 workers in Germany. The findings were ambiguous. Whereas autonomy in working time had a positive effect on job satisfaction, the majority of workers felt dissatisfied with the remaining leisure time. Working time autonomy led to long working hours.

The next article reports on female teleworkers in Spain and their handling of working time and work-life balance. In their study, Ana Gálvez, Francisco Tirado and JoseManuel Alcaráz found that women develop different approaches to relating telework to their time. The women differentiated between 'gendered time' and 'resistance time'.

Anita Tisch, Grit Müller and Anne Wöhrmann examined the effects of long working hours on the health of employees. In a representative survey of 13,452 German employees they found a strong relation between long working hours and psychosomatic health complaints. In their conclusions, the authors ask for lower work intensity and shorter working hours to advance the psychosomatic health of employees. 
In a similar vein, Bernd Frick, Robert Simmons and Friedrich Stein conducted a study in a large automobile plant on the relationship between shift work and absenteeism and employee health. Facing problems with workers' health and high absence rates, the company introduced a new shift system with less health risks. Absence rates dropped significantly. However, after a while workers started to express dissatisfaction with the new shift system. Thereafter, the company returned to a shift system similar to the initial one. The absence rates increased again. The study illustrates the problems when introducing health-oriented work designs.

Lucia Rotenberg and Elisa Carlos elaborate in their research note on the social acceleration theory. They examine the effects of acceleration on Brazilian university teachers. They report in particular on a resulting conflict of values; teachers felt alienated from their professional ideals and convictions. The authors conclude that universities should not be transformed into enterprises, otherwise they are likely to lose their basic mission.

This research note is followed by a resumé of the panel discussion as one of the highlights of the Organizational Working Time Regimes conference on 30-31 March 2017 at the University of Graz, Austria. Panelists were Jana Costas, Susanne Ekman, Laura Empson and Dan Kärremann. The panel covers the most recent and pressing issues of the current debates in time theory. The panelists shed light on time issues from different perspectives. Their controversial views surface different lines of reasoning in the current debates.

In a closing essay, Mats Alvesson and Katja Einola discuss excessive work regimes and point out that we cannot see them as entirely negative; there are positive aspects as well. Some people simply like them and organizations profit from them. The authors make it clear, however, that there is no such thing as a natural working time regime; it is all social construction and therefore changeable. The authors claim that creating a working time regime should follow reflection and not 'functional stupidity'.

\section{Outlook and future research directions}

Based on the findings of the contributions in this special issue and on our own considerations outlined in this introduction, we highlight several avenues for future research that could contribute significantly to our current knowledge.

\section{Understanding the genesis and the historicity of organizational working time regimes}

First, we know surprisingly little about the genesis of organizational regimes of excessive working hours. Why is it that even within the same industry, some organizations come to develop such regimes and others do not? Previous research has tended to take an already existing working time regime as a starting point, usually attributing its existence to an overarching norm of working long hours. However, as pointed out by Alvesson: ' $[\mathrm{t}]$ he norms of the workplaces/occupations [...] are themselves in need of explanation. Where do they come from?' (Alvesson, 2000: 1105; emphasis added). Understanding the genesis and historical evolution of regimes of excessive working hours is not only 
interesting per se. Elucidating the genesis of the norm of long working hours is also a promising avenue for analysing the organizational processes and dynamics that could explain their rigidity.

\section{How do factors across multiple levels of analysis intermingle?}

Second, the bulk of the available studies focuses on single levels of analysis. Considerations of how multiple levels interact are largely missing from most analyses. In the rare cases where more than one level is considered in the explanations, the higher level is usually conceived as a contextual factor that influences the regime's reproduction, for instance in terms of 'organizational support', 'the social structure of workplaces' or as a 'social context' of work. Conceiving a higher level of analysis as a context implies treating it, in principle, as a static exogenous determinant. However, working time regimes involve the mutual constitution of social forces on multiple levels of analysis and not their determination by exogenous forces. Ignoring this insight does not take into account that 'seemingly enduring [...] managerial concepts and structures are underpinned by dynamic activity and processes' (Langley et al., 2013: 10). Much can be gained by future research focusing more explicitly on and illuminating these hitherto undertheorized cross-level processes that could account for the persistence and/or change of organizational working time regimes.

\section{What kind of theories can help us explain the extreme persistence of organizational working time regimes?}

Finally, the majority of previous studies focus on change initiatives. There is surprisingly little research that explicitly addresses the problem of persistence that causes such initiatives to fail systematically (Kellogg, 2012). Usually, persistence is either taken for granted or equated with (individual-level) resistance to change. The dispersed character of time regimes, however, indicates that more complex dynamics on the organizational level are of salient importance here. At the same time, a large body of literature within organization studies has focused on explaining precisely this type of systemic organizational rigidities and persistence (Marquis and Tilcsik, 2013; Staw et al., 1981; Sydow et al., 2009; Tripsas and Gavetti, 2000). Relating this literature to the relevant questions is likely to provide novel insights into the persistence of organizational working time regimes.

Concerning the inertial dynamics at the organizational level, the notion of organizational path dependence might offer a particularly fruitful explanation (David, 1985, 1994; Schreyögg and Sydow, 2011). The path dependence lens raises the question of whether there are hidden organizational drivers that create strong but subtle and often invisible barriers to change. In essence, path dependence theory highlights how 'pattern[s] of action and reflection' (Koch, 2011: 339) in organizations can become locked in as a result of self-reinforcing dynamics triggered by historically contingent events (Arthur, 1994; Dobusch and Schüßler, 2013). Hence, as it directs our attention towards the historicity of working time regimes, path dependence theory is a particularly suitable candidate for future research. 


\section{Funding}

The authors acknowledge the financial support for Open Access publication by the University of Graz.

\section{References}

Acker J (1990) Hierarchies, jobs, bodies: A theory of gendered organizations. Gender \& Society 4(2): 139-158.

Acker J (2006) Inequality regimes. Gender, class, and race in organizations. Gender \& Society 20(4): 441-464.

Alvesson M (2000) Social identity and the problem of loyalty in knowledge-intensive companies. Journal of Management Studies 37(8): 1101-1124.

Alvesson M (2004) Knowledge Work and Knowledge-intensive Firms. New York: Oxford University Press.

Ancona D and Chong CL (1996) Entrainment: Pace, cycle, and rhythm in organizational behavior. Research in Organizational Behavior 18(1): 251-284.

Anderson-Gough F, Grey C and Robson K (2001) Tests of time: Organizational time-reckoning and the making of accountants in two multi-national accounting firms. Accounting, Organizations and Society 26(2): 99-122.

Arthur WB (1994) Increasing Returns and Path Dependence in the Economy. Ann Arbor, MI: University of Michigan Press.

Bailyn L (2006) Breaking the Mold: Redesigning Work for Productive and Satisfying Lives. Ithaca, NY; London: Cornell University Press.

Barley SR, Meyerson DE and Grodal S (2011) E-mail as a source and symbol of stress. Organization Science 22(4): 887-906.

Blair-Loy M (2003) Competing Devotions: Career and Family among Women Executives. Cambridge, MA; London: Harvard University Press.

Brivot M, Lam H and Gendron Y (2014) Digitalization and promotion: An empirical study in a large law firm. British Journal of Management 25(4): 805-818.

Cech EA and Blair-Loy M (2014) Consequences of flexibility stigma among academic scientists and engineers. Work and Occupations 41(1): 86-110.

Costas J and Grey C (2014) The temporality of power and the power of temporality: Imaginary future selves in professional service firms. Organization Studies 35(6): 909-937.

Costas J, Blagoev B and Kärreman D (2016) The arena of the professional body: Sport, autonomy and ambition in professional service firms. Scandinavian Journal of Management 32(1): $10-19$.

Covaleski MA, Dirsmith MW, Heian JB and Samuel S (1998) The calculated and the avowed: Techniques of discipline and struggles over identity in big six public accounting firms. Administrative Science Quarterly 43(2): 293-327.

Crary J (2013) 24/7: Late Capitalism and the Ends of Sleep. London and New York: Verso.

David PA (1985) Clio and the economics of QWERTY. American Economic Review 75(2): $332-337$.

David PA (1994) Why are institutions the 'carriers of history'? Path dependence and the evolution of conventions, organizations and institutions. Structural Change and Economic Dynamics 5(2): 205-220.

Davies AR and Frink BD (2014) The origins of the ideal worker: The separation of work and home in the United States from the market revolution to 1950. Work and Occupations 41(1): 18-39.

Dobusch L and Schüßler E (2013) Theorizing path dependence: A review of positive feedback mechanisms in technology markets, regional clusters, and organizations. Industrial and Corporate Change 22(3): 617-647. 
Dumas TL and Sanchez-Burks J (2015) The professional, the personal, and the ideal worker: Pressures and objectives shaping the boundary between life domains. Academy of Management Annals 9(1): 803-843.

Ekman S (2013) Fantasies about work as limitless potential: How managers and employees seduce each other through dynamics of mutual recognition. Human Relations 66(9): 1159-1181.

Gascoigne C, Parry E and Buchanan D (2015) Extreme work, gendered work? How extreme jobs and the discourse of 'personal choice' perpetuate gender inequality. Organization 22(4): 457-475.

Goh J, Pfeffer J and Zenios SA (2016) The relationship between workplace stressors and mortality and health costs in the United States. Management Science 62(2): 608-628.

Golden L (2009) A brief history of long work time and the contemporary sources of overwork. Journal of Business Ethics 84(2): 217-227.

Grey C (1994) Career as a project of the self and labour process discipline. Sociology 28(2): 479-497.

Hewlett SA and Luce CB (2006) Extreme jobs. Harvard Business Review 84(12): 49-59.

Hobson B and Sadar NČ (2014) Worklife Balance: The Agency \& Capabilities Gap. Oxford: Oxford University Press.

Kärreman D and Alvesson M (2004) Cages in tandem: Management control, social identity, and identification in a knowledge-intensive firm. Organization 11(1): 149-175.

Kärreman D and Alvesson M (2009) Resisting resistance: Counter-resistance, consent and compliance in a consultancy firm. Human Relations 62(8): 1115-1144.

Kellogg KC (2011) Challenging Operations: Medical Reform and Resistance in Surgery. Chicago, IL; London: University of Chicago Press.

Kellogg KC (2012) Making the cut: Using status-based countertactics to block social movement implementation and microinstitutional change in surgery. Organization Science 23(6): 15461570.

Kelly EL, Moen P, Oakes JM, et al. (2014) Changing work and work-family conflict: Evidence from the work, family, and health network. American Sociological Review 79(3): 485-516.

Koch J (2011) Inscribed strategies: Exploring the organizational nature of strategic lock-in. Organization Studies 32(3): 337-363.

Kossek EE, Baltes BB and Matthews RA (2011) How work-family research can finally have an impact in organizations. Industrial and Organizational Psychology 4(3): 352-369.

Kremser W and Schreyögg G (2016) The dynamics of interrelated routines: Introducing the cluster level. Organization Science 27(3): 698-721.

Kunda G (1992) Engineering Culture: Control and Commitment in a High-tech Corporation. Philadelphia, PA: Temple University Press.

Langley A, Smallman C, Tsoukas H and Van den Ven AH (2013) Process studies of change in organization and management: Unveiling temporality, activity, and flow. Academy of Management Journal 56(1): 1-13.

Lupu I and Empson L (2015) Illusio and overwork: Playing the game in the accounting field. Accounting, Auditing \& Accountability Journal 28(8): 1310-1340.

Marquis C and Tilcsik A (2013) Imprinting: Toward a multilevel theory. Academy of Management Annals 7: 195-245.

Mazmanian M (2013) Avoiding the trap of constant connectivity: When congruent frames allow for heterogeneous practices. Academy of Management Journal 56(5): 1225-1250.

Mazmanian M and Erickson I (2014) The product of availability. Understanding the economic underpinnings of constant connectivity. In: CHI 2014: One of a CHInd - Conference Proceedings, 32 $2^{\text {nd }}$ Annual ACM Conference on Human Factors in Computing Systems, New York, 26 April-1 May 2014. New York: ACM Press, pp. 763-772. 
Mazmanian M, Orlikowski WJ and Yates J (2013) The autonomy paradox: The implications of mobile email devices for knowledge professionals. Organization Science 24(5): 1337-1357.

Meiksins P and Whalley P (2004) Putting Work in its Place. Ithaca, NY; London: Cornell University Press.

Meriläinen S, Tienari T, Thomas R and Davies A (2004) Management consultant talk: A crosscultural comparison of normalizing discourse and resistance. Organization 11(4): 539-564.

Michel AA (2011) Transcending socialization: A nine-year ethnography of the body's role in organizational control and knowledge workers' transformation. Administrative Science Quarterly 56(3): 325-368.

Michel AA (2014a) Participation and self-entrapment: A 12-year ethnography of Wall Street participation practices' diffusion and evolving consequences. The Sociological Quarterly 55(3): 514-536.

Michel AA (2014b) The mutual constitution of persons and organizations: An ontological perspective on organizational change. Organization Science 25(4): 1082-1110.

Michel AA (2015) Dualism at work: The social circulation of embodiment theories in use. Signs and Society 3(S1): 41-69.

Moen P (2015) An institutional/organizational turn: Getting to work-life quality and gender equality. Work and Occupations 42(2): 174-182.

Muhr SL (2011) Caught in the gendered machine: On the masculine and feminine in cyborg leadership. Gender, Work and Organization 18(3): 337-357.

Muhr SL and Kirkegaard L (2013) The dream consultant: Productive fantasies at work. Culture and Organization 19(2): 105-123.

Muhr SL, Pedersen M and Alvesson M (2012) Workload, aspiration, and fun: Problems of balancing self-exploitation and self-exploration in work life. In: Holmqvist M and Spicer A (eds) Managing 'Human Resources' by Exploiting and Exploring People's Potentials, Research in the Sociology of Organizations series, Vol. 37. Bingley: Emerald Group Publishing, pp. 193-220.

Ng TWH and Feldman DC (2008) Long work hours: A social identity perspective on meta-analysis data. Journal of Organizational Behavior 29(7): 853-880.

Ortlieb R and Weiss S (2018) What makes academic careers less insecure? The role of individual-level antecedents. Higher Education. EPub ahead of print, 5 January 2018. DOI: 10.1007/s10734 017-0226-x.

Pentland BT (1993) Getting comfortable with the numbers: Auditing and the micro-production of macro-order. Accounting, Organizations and Society 18(7-8): 605-620.

Perlow LA (1997) Finding Time: How Corporations, Individuals, and Families Can Benefit From New Work Practices. Ithaca, NY; London: ILR Press.

Perlow LA (1998) Boundary control: The social ordering of work and family time in a high-tech corporation. Administrative Science Quarterly 43(2): 328-358.

Perlow LA (1999) The time famine: Toward a sociology of work time. Administrative Science Quarterly 44(1): 57-81.

Perlow LA (2012) Sleeping with your Smartphone: How to Break the 24/7 Habit and Change the Way you Work. Cambridge, MA: Harvard Business School Press.

Perlow LA and Kelly EL (2014) Toward a model of work redesign for better work and better life. Work and Occupations 41(1): 111-134.

Perlow LA and Porter JL (2009) Making time off predictable and required. Harvard Business Review 87(10): 102-109.

Pfeffer J (2018) Work hours and health: A comment on 'Beyond nine to five'. Academy of Management Discoveries 4(1): 94-96. 
Pfeffer J and Carney DR (2018) The economic evaluation of time can cause stress. Academy of Management Discoveries 4(1): 74-93.

Putnam LL, Myers KK and Gailliard BM (2014) Examining the tensions in workplace flexibility and exploring options for new directions. Human Relations 67(4): 413-440.

Reid E (2015) Embracing, passing, revealing, and the ideal worker image: How people navigate expected and experienced professional identities. Organization Science 26(4): 997-1017.

Schreyögg G and Sydow J (2011) Organizational path dependence: A process view. Organization Studies 32(3): 321-335.

Snyder BH (2017) The tyranny of clock time? Debating fatigue in the US truck driving industry. Time \& Society. EPub ahead of print, 28 April 2017. DOI: 10.1177/0961463X17701955.

Staw BM, Sandelands LE and Dutton JE (1981) Threat rigidity effects in organizational behavior: A multilevel analysis. Administrative Science Quarterly 26(4): 501-524.

Sydow J, Schreyögg G and Koch J (2009) Organizational path dependence: Opening the black box. Academy of Management Review 34(4): 689-709.

Ten Brummelhuis LL and Rothbard NP (2018) The difference between working long hours and workaholism: Response to commentary on 'Beyond nine to five'. Academy of Management Discoveries 4(1): 97-100.

Ten Brummelhuis LL, Rothbard NP and Uhrich B (2017) Beyond nine to five: Is working to excess bad for health? Academy of Management Discoveries 3(3): 262-283.

Toker S (2018) The economic evaluation of time can cause stress. Academy of Management Discoveries 4(1): 101-102.

Tripsas M and Gavetti G (2000) Capabilities, cognition, and inertia: Evidence from digital imaging. Strategic Management Journal 21(10-11): 1147-1161.

Wajcman J (2014) Pressed for Time: The Acceleration of Life in Digital Capitalism. Chicago, IL: University of Chicago Press.

Wajcman J and Rose E (2011) Constant connectivity: Rethinking interruptions at work. Organization Studies 32(7): 941-961.

Williams JC, Berdahl JL and Vandello JA (2016) Beyond work-life ‘integration'. Annual Review of Psychology 67(1): 515-539.

Williams JC, Blair-Loy M and Berdahl JL (2013) Cultural schemas, social class, and the flexibility stigma. Journal of Social Issues 69(2): 209-234. 